\title{
BMJ Open Experiences of breast feeding at work for physicians, residents and medical students: a scoping review
}

\author{
Alexandra Frolkis, ${ }^{1}$ Allison Michaud, ${ }^{1}$ Khue-Tu Nguyen, ${ }^{1}$ Moss Bruton Joe, ${ }^{2}$ \\ Kirstie Lithgow, ${ }^{1}$ Shannon M Ruzycki (D) ${ }^{1,3}$
}

To cite: Frolkis A, Michaud A, Nguyen K-T, et al. Experiences of breast feeding at work for physicians, residents and medical students: a scoping review. BMJ Open 2020;10:e039418. doi:10.1136/ bmjopen-2020-039418

- Prepublication history and additional material for this paper are available online. To view these files, please visit the journal online (http://dx.doi. org/10.1136/bmjopen-2020039418).

$\mathrm{AF}$ and $\mathrm{AM}$ are joint first authors.

Received 15 April 2020

Revised 24 August 2020

Accepted 02 September 2020

Check for updates

(c) Author(s) (or their employer(s)) 2020. Re-use permitted under CC BY-NC. No commercial re-use. See rights and permissions. Published by BMJ.

${ }^{1}$ Department of Medicine, Cumming School of Medicine, University of Calgary, Calgary, Alberta, Canada

${ }^{2}$ Cumming School of Medicine, University of Calgary, Calgary, Alberta, Canada

${ }^{3}$ Department of Community Health Sciences, Cumming School of Medicine, University of Calgary, Calgary, Alberta, Canada

Correspondence to Dr Shannon M Ruzycki; shannon.ruzycki@ucalgary.ca

\section{ABSTRACT}

Objective To review and summarise the available literature regarding breastfeeding experiences of medical students, residents and physicians.

Eligibility criteria Articles of any design, including non-peer reviewed data that examine the experiences of breast feeding of medical students, residents and staff physicians.

Information sources Ovid MEDLINE(R) and Epub Ahead of Print, In-Process \& Other Non-Indexed Citations and Daily, Ovid EMBASE, Scopus and Web of Science.

Risk of bias All peer-reviewed studies underwent riskof-bias assessment using relevant tools, depending on the study design.

Included studies We included 71 citations; 51 surveys, 3 narrative descriptions, 9 editorials or letters to the editor, and 3 reviews.

Synthesis of results Included articles were heterogeneous with respect to their study design, target population and outcomes reported. Most articles had a high risk of bias. Only five articles reported the impact of an intervention.

Description of effect Despite heterogeneity, the majority of articles described important barriers to breast feeding for physicians, residents and medical students. These barriers were similar across studies, and included inadequate and inaccessible space, time constraints and inflexible scheduling, and lack of colleague support. The consequences of these barriers included low milk supply and early discontinuation of breast feeding.

Strengths and limitations of evidence Due to the observed heterogeneity of articles identified in this review, we are unable to assess trends in barriers or duration of breastfeeding over time.

Interpretation Interventions to overcome systemic and cultural barriers to breast feeding are needed to meet legal obligations of workplaces for physicians and trainees. These interventions should be formally evaluated using implementation science or quality improvement methods.

\section{INTRODUCTION}

The proportion of women trainees and physicians in practice is rising; in Canada, women represent $41 \%$ of the current physician workforce, and for the first time in the USA, medical school classes are predominantly female. ${ }^{12}$ Importantly, women in medicine are

\section{Strengths and limitations of this study}

This is the first scoping review focusing on experiences of breast feeding for physicians, residents and medical students

- The current literature examining experiences of breast feeding for women in medicine is heterogeneous, which limits comparison of studies across populations and over time.

- The bulk of literature consists of survey studies using different instruments and questions, further limiting comparisons across populations.

- Many included surveys did not ask about key themes identified in this scoping review, such as harassment and discrimination, so the scope of these barriers cannot be defined.

- Included studies report breastfeeding duration outcomes using different summary statistics and do not always include measures of variance, preventing meta-analysis.

concentrated in younger age demographics, during the peak of their reproductive years. ${ }^{3}$ Previous studies have identified that physician, resident and medical student mothers face unique and important challenges, including structural barriers, higher rates of work-family conflict and discrimination. ${ }^{4-8}$

Support for mothers in medicine is considered an important area for intervention to reduce the 'leaky pipeline' phenomenon that prevents advancement of women in academia and attainment of leadership roles. ${ }^{9}$ Despite legal protections in many countries that require workplaces to support breast feeding, women physicians have lower rates of meeting their breastfeeding duration goals compared with women in other fields ${ }^{10}$ and consistently report important systems-level barriers to breastfeeding. ${ }^{11}$ We sought to synthesise the current literature examining breast feeding for women in medicine.

The objective of this scoping review was to understand the experiences of breast feeding or expressing breastmilk ('pumping') of 
physicians, residents and medical students. This included characterising their intentions, goals and duration of breast feeding or pumping, as well as identifying barriers and facilitators of breast feeding or pumping in this population. In addition, we sought to identify evidencebased interventions that may support breast feeding or pumping for women in medicine. Based on these broad aims, we selected a scoping review methodology. ${ }^{12} 13$ The overall aim of this scoping review was to use the existing literature to inform local policies, advocacy work and development of interventions to support breast feeding or pumping for women in medicine.

\section{METHODS}

A scoping review protocol was developed using the Joanna Brigg's Institute methodology ${ }^{13}$ (see online supplemental appendix 1). We followed the Preferred Reporting Items for Systematic Reviews and Meta-Analyses extension for Scoping Reviews guidelines in reporting our protocol and results. Scoping review methods are useful for topics that are complex or have heterogeneous literature and employ rigorous search strategies and data extraction methods to map the existing literature. ${ }^{12}$ Scoping reviews can summarise a field, identify gaps for future research and guide future projects. ${ }^{12}$

\section{Systematic literature search}

A preliminary search strategy was developed with the aid of a medical librarian. Our full search strategy and terms are available in online supplemental appendix 1. Citations were found by searching the following databases from inception to 15 October 2019: Ovid MEDLINE(R) and Epub Ahead of Print, In-Process \& Other NonIndexed Citations and Daily, Ovid EMBASE, Scopus and Web of Science. Additional articles were identified by handsearching the reference lists of all included articles and were additionally solicited from key informants. We solicited unpublished conference abstracts or suggestions for additional citations by posting on the Facebook group 'MILK', an international group for physician mothers to discuss and provide support about lactation. ${ }^{14}$

\section{Inclusion criteria}

We considered articles of any study type eligible, including observational studies, qualitative studies, intervention studies, quality improvement studies, environmental scans, editorials or commentaries, letters to the editor, narrative descriptions and non-peer reviewed data. All study types were included to ensure comprehensive synthesis of all barriers, facilitators, interventions and themes related to experiences of breast feeding at work for physicians and residents. The study population had to include physician, resident or medical student mothers who had children after starting medical training, and the data reported had to include experiences or perceptions of breast feeding or expressing breast milk ('pumping') by physician, resident or medical student mothers.
Articles were excluded if they solely reported on physicians' or trainees' knowledge of breast feeding or clinical practices related to breast feeding. Articles were also excluded after full-text screening if they reported duplicate data presented elsewhere. When articles reported outcomes for study populations that also included participants other than our target population, we contacted the authors of the articles to obtain stratified data for physician, resident or medical student mothers. If this was not available, we did not include the data in our analysis.

\section{Study selection}

All identified citations were downloaded to EndNote X9 (Clarivate Analytics USA; V.19.0.012062) and deduplicated. Any identified non-English articles were translated for review and data abstraction. Two authors reviewed independently screened abstracts for eligibility; articles without abstracts were screened in totality for eligibility. Disagreements about whether an article met inclusion criteria were resolved by a third reviewer.

\section{Data extraction}

A data extraction tool was created by three members of the study team after each screened a sample of 20 articles of different study types for common themes and reported outcomes (see online supplemental appendix 2). The three study team members listed all outcomes and themes reported in their sample. Themes were included in the data extraction tool if identified by all three study team members: (1) duration of maternity leave; (2) colleague support; (3) harassment and discrimination related to breast feeding or pumping; (4) time constraints for pumping at work and (5) structural supports for pumping at work. Additional themes were classified as 'Other' and space was included for extraction of further details. The data extraction tool also contained sections for article demographics, duration of breast feeding using multiple measures and space for additional reported outcomes. The data extraction tool was piloted with all study team members who abstracted data, and adjustments were made as needed. Data from all studies were extracted independently by two study team members. Data extraction was reconciled, and differences were resolved by consulting the primary article. Any remaining disagreements were arbitrated by a third reviewer.

Outcomes of interest were measures of breast feeding or pumping, including intention to breastfeed, goal duration of breastfeeding and actual duration of breast feeding. Each theme, if reported, was categorised as a 'barrier' or 'facilitator' based on the result of the study.

\section{Risk-of-bias assessment}

All peer-reviewed studies underwent risk-of-bias assessment using the CLARITY Group Risk of Bias Instrument for Cross-Sectional Surveys of Attitudes and Practices ${ }^{15}$ for survey data, the Critical Appraisal Skills Programme Checklist for Qualitative Research ${ }^{16}$ for interview and qualitative data, and the National Institute of Health's 


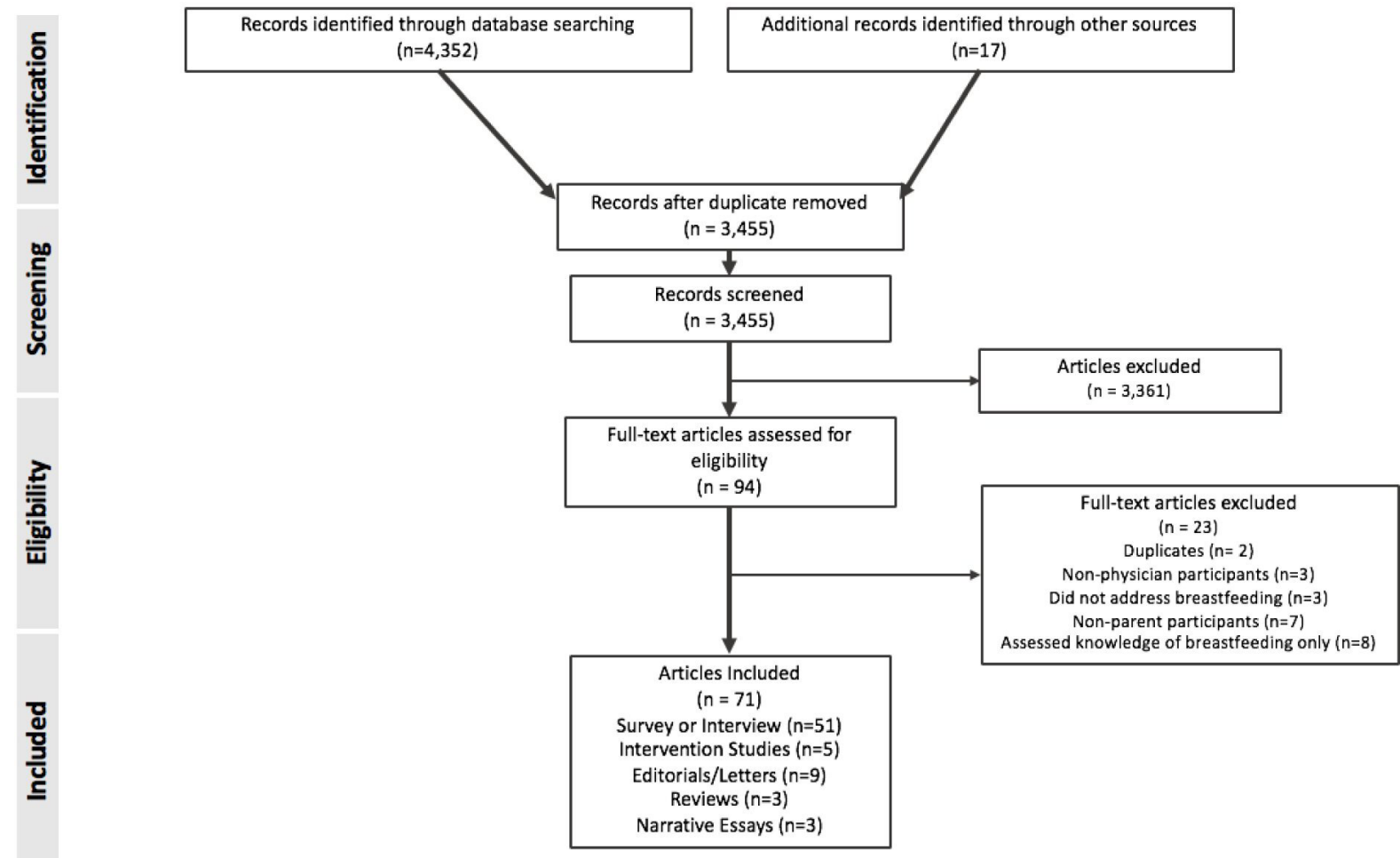

Figure 1 Flow diagram of included studies.

Quality Assessment Tool for Before-After (Pre-Post) Studies with No Control Group tool ${ }^{17}$ for pre/postintervention study designs. Critical appraisal was performed in order to understand potential biases and limitations of the data but did not inform analysis otherwise.

\section{Patient and public involvement}

Patients and the public were not involved in the design of this project and were not involved in drafting or editing the manuscript.

\section{RESULTS}

The search strategy identified 4369 total citations; 4352 abstracts from database searching, 15 from handsearching and 2 from the grey literature (figure 1). There were 3455 citations remaining after duplicates were removed, and 94 were included for full-text review after abstract screening. After full-text review, 71 citations were included in the analysis (table 1 ; for a full list of included citations, please see online supplemental appendix 3).

\section{CHARACTERISTICS OF ARTICLES \\ Surveys and interviews}

Seventy-two per cent of included studies used survey or interview methods $(\mathrm{n}=51$; table 1$)$. There was considerable heterogeneity in the study populations, survey instruments used and outcomes reported. Most studies included only residents $(\mathrm{n}=22 ; 43.1 \%)^{18-40}$ but 10 included a combination of faculty statuses $(19.6 \%)^{41-51}$ (table 2). Most studies combined participants from different practice disciplines $(\mathrm{n}=28 ; 54.9 \%),{ }^{20-22} 27323536394142444550-66$ while the remaining studies reported on participants from a single discipline. When combining practice disciplines, procedural and non-procedural disciplines were often combined. For some studies, the unit of analysis ('participant') was per physician or trainee mother, while others analysed number of pregnancies or children. Considering this, the median number of participants in included studies was 126 (IQR 50-234). We observed a wide range of response rates for survey data (range $6.01^{18}-89.3 \%^{57}$; median $41.0 \%$, IQR $25.6 \%-$ $64.0 \%$ ). For 20 studies $(39.2 \%)$, no response rate was reported. $^{21} 252730-323637424850535456585961636566$ The majority of survey studies were found to have a low risk of bias $(\mathrm{n}=29 ; 56.9 \%)$ (see online supplemental appendix $3)$.

Measures of breast feeding (intention to, initiation of and duration of breast feeding or pumping) and included study populations (procedural and non-procedural disciplines or trainees and staff physicians) were too heterogeneous to allow combination of these data. While many studies reported mean duration of breastfeeding, some reported the median duration. Further, many studies did not include a measure of variance (eg, an SD or IQR) for the duration of breast feeding.

\section{Intervention studies}

We identified five studies that described or evaluated the impact of an intervention on breastfeeding outcomes for physicians or residents ${ }^{145167-69}$ (table 3). Three studies were narrative descriptions of interventions without 
Table 1 Characteristics of citations included in this scoping review

\begin{tabular}{lc}
\hline Characteristics & No (\%) \\
\hline Total citations & 71 \\
Publication year & \\
\hline$<2000$ & $3(4.2)$ \\
\hline $2000-2004$ & $7(9.9)$ \\
\hline $2005-2009$ & $7(9.9)$ \\
\hline $2010-2014$ & $21(29.6)$ \\
\hline $2015-2019$ & $32(45.1)$ \\
\hline 2020 & $1(1.4)$ \\
\hline Publication type & \\
\hline Survey or interview & $51(71.8)$ \\
\hline Intervention studies & $5(7.0)$ \\
\hline Editorial/comment & $9(12.7)$ \\
\hline Narrative essays & $3(4.2)$ \\
\hline Review & $3(4.2)$ \\
\hline Systematic search strategy & $1(1.4)$ \\
\hline Non-systematic search strategy & $2(2.8)$ \\
\hline Country(ies) & \\
\hline USA & $53(74.6)$ \\
\hline Canada & $9(12.7)$ \\
\hline USA and Canada & $1(1.4)$ \\
\hline Australia & $2(2.8)$ \\
\hline Turkey & $2(2.8)$ \\
\hline Nigeria & $2(2.8)$ \\
\hline International/multiple countries & $1(1.4)$ \\
\hline Europe & $1(1.4)$ \\
\hline & \\
\hline
\end{tabular}

comparison groups or formal evaluation; one described a peer-support Facebook group for breastfeeding physicians $^{14}$ and two described development of dedicated lactation spaces for hospital workers. ${ }^{6} 69$

One study was a pre/postintervention study using semistructured interviews to assess the impact of providing a hospital-grade breast pump in a dedicated lactation space on breastfeeding outcomes. ${ }^{67}$ The study included data from six residents; all reported significantly less time spent pumping and increased milk expression per session after the intervention. The participants also reported reduced anxiety about pumping at work and fewer negative comments from colleagues about time spent pumping.

A second study was a pre/postintervention survey assessing the impact of a change in Turkey's laws about parental leave on breastfeeding outcomes for women physicians. ${ }^{51}$ Maternity leave accommodations were expanded in Turkey in 2012; these included more flexible work hours for 6 months after returning to work and a ban on night shifts from disclosure of pregnancy until 24 months after birth. The survey demonstrated an increase in breastfeeding duration of about 4 months,
Table 2 Characteristics of citations that used survey or interview methods

\begin{tabular}{|c|c|}
\hline Characteristic & No (\%) \\
\hline Total citations & 51 \\
\hline \multicolumn{2}{|l|}{ Location of citation } \\
\hline USA & $34(66.7)$ \\
\hline Canada & $8(15.7)$ \\
\hline USA and Canada & $1(2.0)$ \\
\hline Australia & $2(3.9)$ \\
\hline Turkey & $2(3.9)$ \\
\hline Nigeria & $2(3.9)$ \\
\hline Europe & $1(2.0)$ \\
\hline Multiple & $1(2.0)$ \\
\hline \multicolumn{2}{|l|}{ No of participants* } \\
\hline$\leq 50$ & $13(25.5)$ \\
\hline $51-99$ & $14(27.5)$ \\
\hline $100-149$ & $8(15.7)$ \\
\hline $150-199$ & $6(11.8)$ \\
\hline 200-499 & $5(9.8)$ \\
\hline 500-999 & $4(7.8)$ \\
\hline$\geq 1000$ & $1(2.0)$ \\
\hline \multicolumn{2}{|l|}{ Response rate } \\
\hline$<10 \%$ & $3(5.9)$ \\
\hline $10 \%-29 \%$ & $6(11.8)$ \\
\hline $30 \%-49 \%$ & $10(19.6)$ \\
\hline$\geq 50 \%$ & $12(23.5)$ \\
\hline Not reported & $20(39.2)$ \\
\hline \multicolumn{2}{|l|}{ Faculty status of participants } \\
\hline Medical students & 0 \\
\hline Residents & $22(43.1)$ \\
\hline Staff & 19 (37.3) \\
\hline Combination of trainees and staff & $10(19.60$ \\
\hline \multicolumn{2}{|l|}{ Discipline of practice } \\
\hline Anaesthesia & $1(2.0)$ \\
\hline Cardiology & $2(3.9)$ \\
\hline Emergency medicine & $1(2.0)$ \\
\hline Family medicine & $5(9.8)$ \\
\hline General surgery & $2(3.9)$ \\
\hline Infectious disease & $1(2.0)$ \\
\hline Internal medicine & $1(2.0)$ \\
\hline Obstetrics and gynaecology & $2(3.9)$ \\
\hline Orthopaedic surgery & $1(2.0)$ \\
\hline Otolaryngology & $1(2.0)$ \\
\hline Paediatrics & $2(3.9)$ \\
\hline Radiation oncology & $1(2.0)$ \\
\hline Urology & $1(2.0)$ \\
\hline Surgical disciplines & $2(3.9)$ \\
\hline Combination of disciplines & 28 (54.9) \\
\hline
\end{tabular}

*Number of breastfeeding mothers, not necessarily the total participants in the study. 


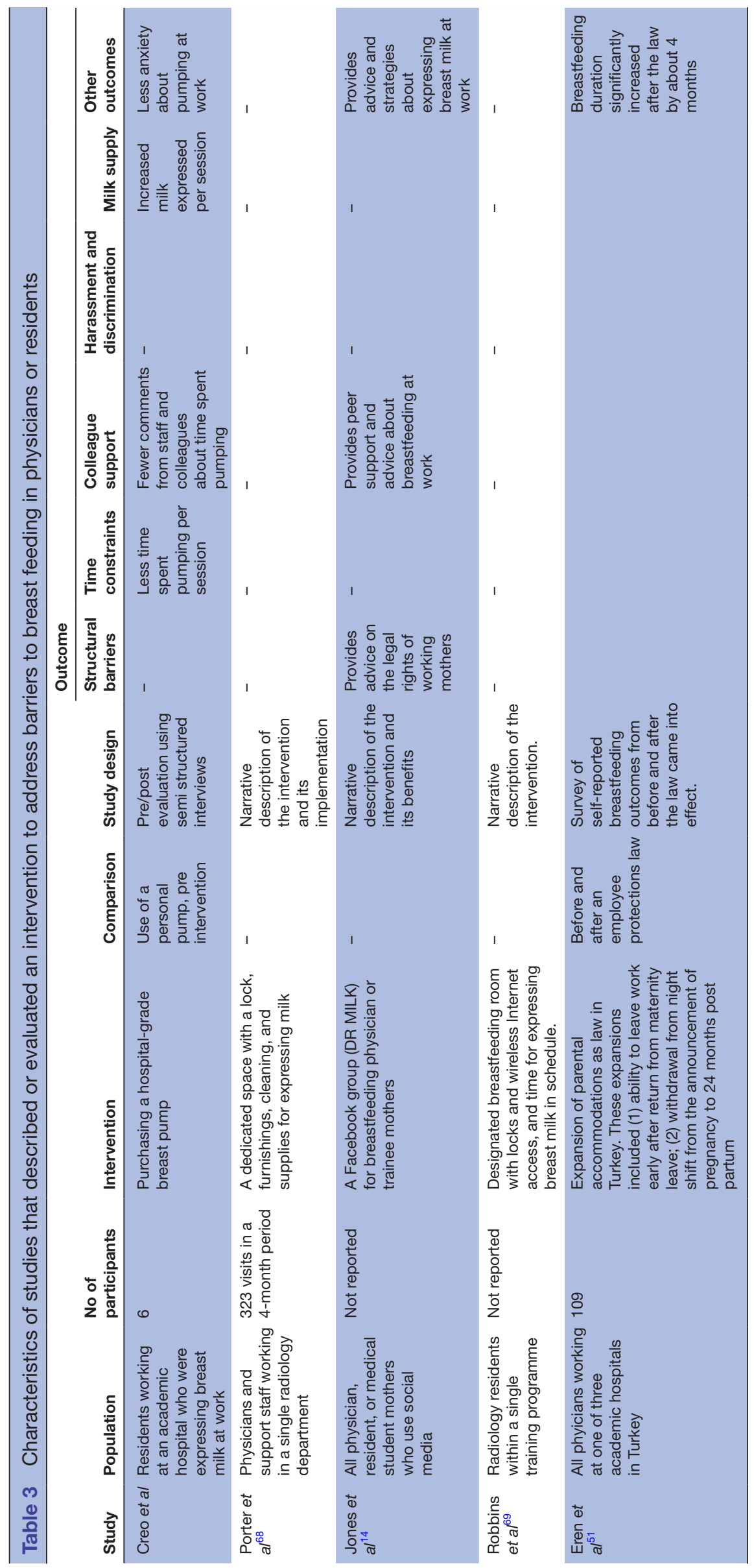


depending on the physicians' specialty, which was statistically significant.

\section{Narrative reviews}

We identified no systematic reviews or reviews with a systematic search strategy or clearly defined inclusion or exclusion criteria that addressed our study question. We identified two reviews that focused predominately on parental leaves ${ }^{70}$ and pregnancy ${ }^{71}$ in physicians, and a single review of breastfeeding for physicians. ${ }^{10}$ This narrative review, published in 2010, compared data on breastfeeding in physicians to the general public, and concluded that women physicians were a high-risk group for low breastfeeding rates. ${ }^{10}$ No review provided any additional data or themes.

\section{Editorials}

The search strategy identified four editorials ${ }^{72-75}$ and five letters to the editor. ${ }^{60}{ }^{76-79}$ Five contained additional, nonpeer reviewed data or shared local policies designed to facilitate breastfeeding or pumping. ${ }^{60} 68747578$ Of note, the earliest editorial that called for institutions to better accommodate breastfeeding residents was published in 1982. ${ }^{79}$ Three shared personal experiences with barriers and called for structural supports. ${ }^{72} 7376$ Five were written by physician mothers. ${ }^{7376778081}$ All themes from editorials or letters were already identified in our review of data from survey and interview studies.

\section{Narrative descriptions}

We identified three narrative descriptions of experiences of parenthood or breastfeeding written by a single author. ${ }^{80-82}$ The only new theme that emerged was the challenge of increased cognitive load related to pumping at work while simultaneously managing clinical issues, which was described by one author. ${ }^{81}$

\section{Breastfeeding outcomes \\ Intended to breastfeed}

Proportions of physicians and trainees who intended to breastfeedwere greater than $90 \%$ inallsurveys thatreported this outcome (n=13) (figure 2). ${ }^{10242632343646-4851535683}$

\section{Initiated breast feeding}

Similarly, proportions of physicians and trainees who initiated breast feeding were greater than $75 \%$ in most surveys that reported this outcome $(n=30)$ (figure 2). 202123 25-27 $3436383941425355576284-88$

\section{Duration of breast feeding}

Comparing the duration of breast feeding between studies is limited by heterogeneity in reporting of this outcome and the study population. Breastfeeding duration outcomes were reported as means, medians, percent breast feeding at 6 months, and per cent breast feeding at 12 months, among other measures. Not all studies reported measures of variance when reporting a mean or median. Further, it is likely that the distribution of duration of breastfeeding is non-parametric, suggesting that

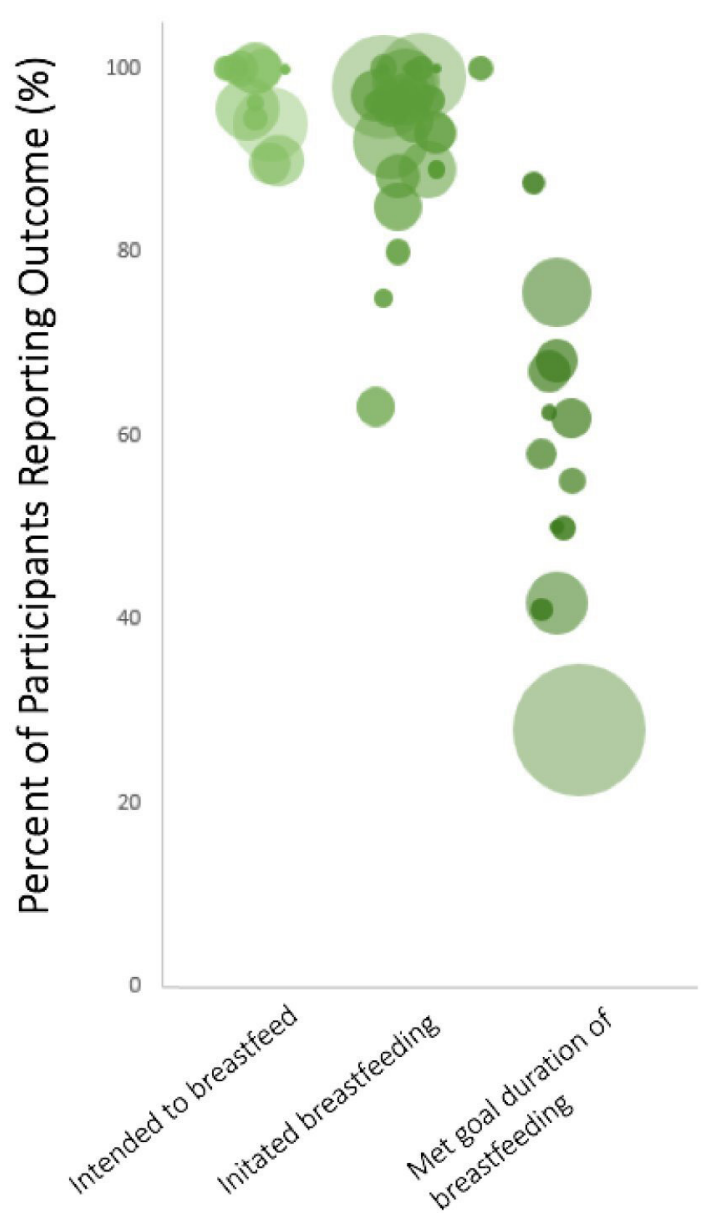

Figure 2 Rates of study participants that reported each breastfeeding outcome by individual study. Each study is represented by one circle, with the size of the circle is proportional to the number of participants in that study.

reporting a mean is less informative than a median duration. Other outcomes, including per cent breast feeding at various durations less than 6 months, rates of exclusive breast feeding versus any breast feeding, and absolute ranges, were also reported in the literature. Altogether, these limitations should be considered when interpreting the overall durations of breast feeding reported for physicians and trainees.

In general, residents appeared to breastfeed for a shorter duration than staff physicians (figure 3). Overall, most studies reported a median or average duration of breast feeding that was 6 months for residents $(n=7)$ (figure 3A). ${ }^{18} 293336485285$ For resident physicians, most studies reported rates of breastfeeding at 6 months that were less than $50 \%(\mathrm{n}=12)^{182023252729323438398389}$ and rates at 12 months that were around $30 \%(n=9)^{202325272932343989}$ (figure 3B). There were some outliers that reported higher rates of breastfeeding; however, most of these studies had fewer than 10 participants.

There was considerable range of breast feeding duration for staff physicians reported across studies included in this review (figure 3). This variation is, in part, due to differences in study population (mixed discipline vs single discipline), discipline of practice (procedural vs 

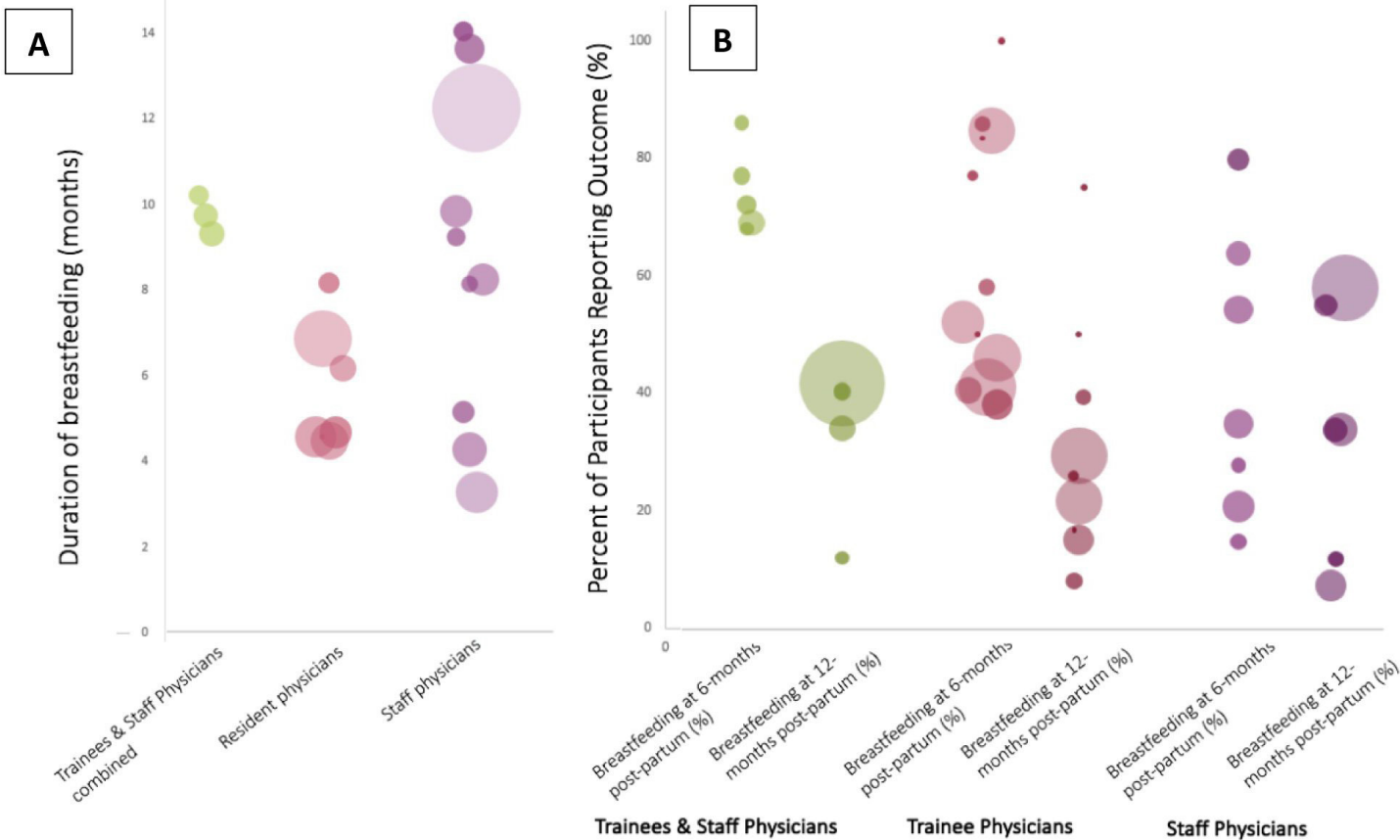

Figure 3 Duration of breast feeding reported by individual studies, stratified by faculty status of participants. Each study is represented by one circle, with the size of the circle is proportional to the number of participants in that study. (A) depicts studies that reported duration of breast feeding as a continuous variable and (B) depicts studies that reported duration of breast feeding as a categorical variable.

non-procedural) and country of study. Overall, it appears that most staff physicians breastfed for less than 12 months.

\section{Met breastfeeding duration goals}

The proportion of participants that met their goal breastfeeding duration varied widely between different studies (figure 2). ${ }^{1821243640434446475288} 89$ This was attributed to heterogeneous study populations and variability in how this outcome was measured and reported. The survey with the largest number of participants $(n=1606)$ found the lowest proportion of participants meeting their goal breast feeding duration, with less than one third of physician mothers meeting their goal. ${ }^{44}$

\section{Themes}

Despite the limitations of data, including the heterogeneity of the study populations and the heterogeneity of how outcomes were collected across articles identified in this review, we identified several consistent themes (figure 4).

\section{Sociocultural support for breast feeding or pumping}

Sociocultural support for breast feeding or pumping was manifested by two subthemes; lack of colleague support, referring to general comments or expressed annoyance due to a participant's need to pump at work; and harassment and discrimination, which referred to comments or actions that unjustly targeted participants for pumping at work.

Fourteen of the survey studies reported data on colleague support for breast feeding or pumping. ${ }^{18232427283243454651535889}$ The proportion of participants who reported lack of colleague support as a barrier to breastfeeding ranged from greater than $80 \%{ }^{54}$ to less than $5 \%{ }^{27}$; however, most studies reported that between $20 \%$ and $60 \%$ of participants felt that their colleagues were not supportive of breastfeeding (figure 4). Many studies reported a perceived lack of support from peers, who had to cover duties while participants expressed breastmilk,,$^{33} 34$ as well as a lack of support from leadership, including programme directors ${ }^{31}$ or attending physicians who expressed that pumping was clinically inconvenient. ${ }^{263334}$ Participants reported discomfort with asking their attending staff physician for time away from clinical duties to pump breastmilk. ${ }^{54}$ Increasing perceived support for breastfeeding was associated with a longer duration of breast feeding. ${ }^{53}$

Six studies examined harassment and discrimination related to breast feeding at work. ${ }^{24} 3140565890$ Three of these studies reported narratively on harassment and discrimination experienced by participants related to breast feeding or pumping ${ }^{3140} 56$ without reporting a rate. Three studies reported rates of harassment and discrimination that were greater than 20\% ${ }^{5459}$ (figure 4). Importantly, one of these citations is published in abstract-only form ${ }^{59}$ and a second is a non-peer-reviewed report. ${ }^{58}$ From these studies, examples of harassment and discrimination included receiving a low evaluation referencing the resident's need to pump, ${ }^{58}$ being told that pumping at work indicated that she was less dedicated to her job, ${ }^{58}$ and being restricted from pumping during an examination. ${ }^{43}$ 


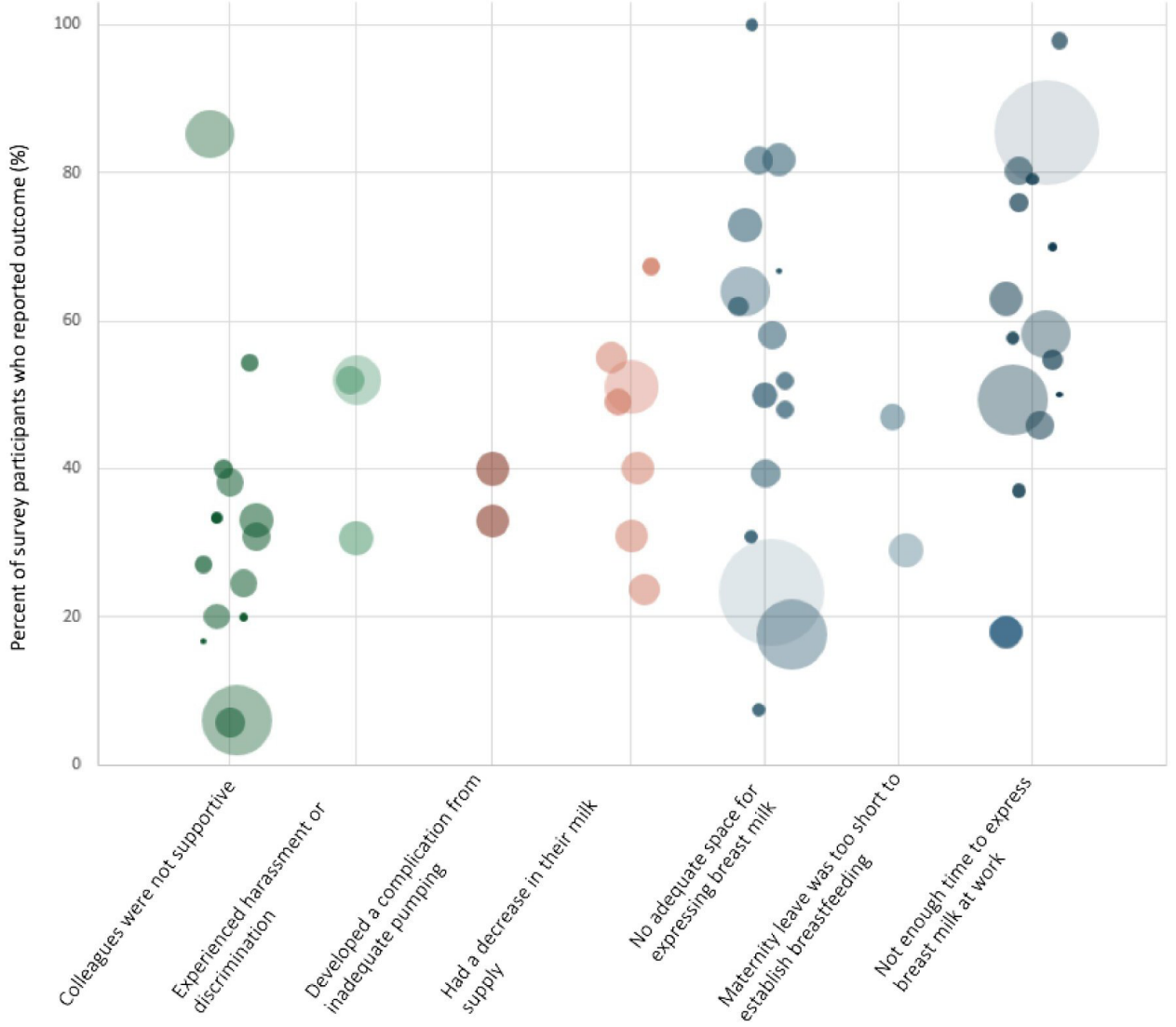

Figure 4 Barriers to breast feeding at work reported by individual studies. Each study is represented by one circle, with the size of the circle is proportional to the number of participants in that study.

Complications from inadequate breastmilk expression

Complications from inadequate breastmilk expression was subdivided into two major themes; low milk supply and medical complications, including clogged ducts, mastitis and breast abscess.

Few studies reported on complications from inadequate breastmilk expression (figure 4). Two surveys that included medical complications related to inadequate breastmilk expression reported rates between $35 \%$ and $40 \% .{ }^{586}$ Seven studies that reported on rates of low breastmilk supply after return to work found that this impacted between $20 \%$ and $65 \%$ of all participants. ${ }^{18364653868891}$ Participants often linked reduced breastmilk expression as a consequence of other barriers that interfered with pumping.

\section{Structural or systems-level barriers to breast feeding or pumping}

The majority of survey studies reported outcomes related to at least one structural or systems-level barrier or facilitator of breastfeeding or pumping. The most commonly reported structural barrier was lack of space, followed by inadequacy of provided space, lack of scheduling flexibility to accommodate pumping, lack of time to accommodate pumping, and lack of either maternity leave or lactation policy to guide physicians who returned to work.

Twenty-three studies reported on physical space for breast feeding or pumping while at work. ${ }^{1821232426-283234363742-4749515358838592}$ The proportion of participants who reported lack of physical space as a barrier ranged from less than 10\%-100\%, depending on the study, with wide variability (figure 4). Across many studies, participants noted that designated spaces often were not accessible, there was not adequate storage for breast milk, and there was no access to workspaces for concurrent work while pumping. Many studies included examples of participants expressing breastmilk in their cars or in bathrooms. 7377686

Fifteen studies reported an outcome related to adequacy of time available at work for breastfeeding or pumping 21232427283236434446475658868991 ; the majority of studies found that most participants did not have adequate time (figure 4). Participants also reported that scheduling flexibility was desired to avoid engorgement and reduced breastmilk supply. ${ }^{46}$ In two studies, participants who reported adequate schedule time and flexibility breastfed for significantly longer than those who did not. $^{5393}$

\section{Duration of maternity leave}

Longer duration of maternity leave was consistently associated with increased duration of breastfeeding, both qualitatively and quantitatively. ${ }^{22} 2733$ 43-45 47-49 $5253748386-89$ In some studies, participants reported pressure from their residency programmes or colleagues to return to work sooner than they had intended. ${ }^{33} 83$ Participants often returned to work sooner to avoid lengthening their 
residency training, ${ }^{40}$ and one study reported that $45 \%$ of participants who extended their residency training to have a longer maternity leave did so in order to accommodate breast feeding. ${ }^{49}$ In one study, $40 \%$ of residents reported completing graduate studies or research training during their maternity leaves. ${ }^{34}$ Residents whose programmes required them to make up work or call missed due to breast feeding at work breastfed for shorter duration than residents whose programmes did not have such policies. ${ }^{53}$

\section{Differences in outcomes before and after legislation to protect breast feeding at work}

The Patient Protection and Affordable Care Act (ACA) was passed into legislation in the USA in 2010, and contains protections for people who breastfeed at work, including adequate time and space for breastfeeding. ${ }^{94}$ There were 11 studies that completed data collection in the USA before $2010 \quad(\mathrm{n}=1282$ participants; "preACA studies') $)^{21} 33364246-4850555686$ and 15 studies that began data collection after $2010 \quad(\mathrm{n}=2824$, 'post-ACA studies') $^{71819232527444552548384889295}$ (12 studies completed in the USA did not report the time of data collection and 1 study began data collection before 2010 and completed after 2011).

The proportion of participants breast feeding at 6 months ranged from $15 \%^{21}$ to $77 \%^{46}$ in pre-ACA studies and $35 \%^{84}$ to $86 \%^{52}$ in post-ACA studies. Of the 11 pre-ACA studies, all found lack of time to breastfeed at work was a significant barrier for the majority of respondents. Eight of the post-ACA studies report on time for breastfeeding at work and all found that it was a barrier. ${ }^{71819232527444552548384889295}$ Nine of the 11 pre-ACA studies reported participants who did not have adequate space, two outlier studies reported that $42 \%$ and $61 \%$ of respondents 'always' had adequate space for breast feeding at work. ${ }^{46}{ }^{56}$ Ten post-ACA studies reported on adequate space for breast feeding but outcomes for these studies were heterogeneous; for example, in one study, $73 \%$ of respondents felt that a private space to pump breastmilk was important ${ }^{18}$ and in another, while $63 \%$ of participants knew of lactation facilities in their workplace, $44 \%$ of this group reported that they were not close enough to a work space to be usable. ${ }^{54}$ Overall, heterogeneity in data collection and reporting of outcomes limits full comparison of breast feeding at work before and after passing of the ACA.

\section{DISCUSSION}

This scoping review of experiences of breast feeding for women in medicine identified 71 citations that were heterogeneous in terms of their study design, population, number of participants and outcomes measured. Despite these differences, these articles consistently reported systems-level and cultural barriers to breast feeding at work that included lack of adequate and accessible space, lack of colleague support, lack of adequate time and lack of schedule flexibility. The consequences of these barriers were discontinuation of breastfeeding earlier than one's goal duration, medical complications of inadequate breastmilk expression such as mastitis, and low breastmilk supply. High-quality studies that evaluated interventions to reduce barriers to breast feeding for women in medicine are lacking.

In the USA, the Patient Protection and ACA requires employers to provide structural support for women to breastfeed at work, including to "provide reasonable break time for an employee to express breast milk for her nursing child for 1 year after the child's birth each time such employee has need to express the milk, ${ }^{94}$ This Act also specifies that the employer must also provide 'a place, other than a bathroom, that is shielded from view and free from intrusion from coworkers and the public' ${ }^{94}$ Similar laws exist in other countries ${ }^{96}$ though the strength of protections differ. ${ }^{97} 98$ Data collected in this review demonstrates that many hospitals and clinics are not meeting these requirements for women physicians, residents and medical students. Inadequate time and space for breastfeeding at work were frequently identified as barriers. Data collection and outcome heterogeneity between studies limits the ability to compare studies completed before and after passing of the ACA for differences in duration or experiences of breastfeeding.

Lack of structural and cultural support for breast feeding for women physicians was related to early discontinuation of breast feeding. The median duration of breast feeding for resident participants was generally around 6 months in most studies and is probably higher for staff physicians. Resident physicians and medical students may be particularly vulnerable to cultural and structural barriers which interfere with breast feeding and pumping, such as reduced autonomy over scheduling, increased duty hours, and lack of private office space.

The reported data on breast feeding duration appears in keeping with the US national average, which reports $43.4 \%$ of mothers continued to breastfeed at 6 months. ${ }^{99}$ However, this may be an inappropriate benchmark for our study population. Due to presumed knowledge and awareness of the benefits of breast feeding, women in medicine may be more likely to aim for a breastfeeding duration of 6 months or longer as recommended by guidelines ${ }^{100}$ as compared with the general population. Though the breastfeeding duration varied widely across different studies, the largest study reporting this outcome $(n=1606)$ found that less than one third of physician mothers met their goal. ${ }^{44}$

This scoping review has identified that the current literature on experiences of breast feeding for women physicians would benefit from use of a common validated survey instrument to facilitate objective comparisons between different populations and time points. The variation in survey instrument can lead to missing domains of inquiry in individual studies; for example, only two survey studies reported on complications from inadequate pumping and only three reported on harassment or discrimination related to breast feeding. In 
addition, it is difficult to assess trends in the duration of breast feeding for women in medicine over time due to the different measures of duration in the literature. We recommend using non-parametric, continuous data over parametric measures or categorical data to report the duration of breastfeeding in surveys of women in medicine. Lastly, due to the difference in barriers experienced, we suggest stratifying the population studied into faculty status (eg, trainee or staff) and discipline of practice (eg, procedural vs non-procedural) when possible, as these different groups may face unique challenges related to breast feeding.

Our results suggest that the current literature on experiences of breast feeding for women physicians and trainees is saturated, as the vast majority of studies report on the same experiences and barriers. Until these barriers are addressed by institutions, it is unlikely that surveys of individual experiences will provide any new insights for this issue. There is an important gap in the current literature regarding how to implement and evaluate interventions to improve experiences of women physicians. Future studies should use knowledge translation, implementation and theories of behavioural change methodology to evaluate such interventions and examine barriers to effective change.

Medical leaders, including programme directors and hospital administrators, have a responsibility to accommodate breastfeeding at work for physicians and, as such, should aim to address the barriers identified in this review. In particular, medical leaders should identify accessible spaces for breastfeeding that include breastmilk storage and a workstation for physician mothers returning to work, as well as develop novel solutions to address time constraints and schedule inflexibility faced by women in medicine. Further, medical leaders should role model a supportive work environment for breast feeding and should not tolerate discrimination or harassment of breastfeeding physicians.

\section{LIMITATIONS}

This scoping review is limited by the heterogeneity of the included studies. For example, we are unable to determine if there are important differences in barriers and experiences between physicians, residents and medical students, or if there are differences between procedural and non-procedural specialties. Similarly, we are unable to compare breastfeeding duration across studies, populations and over time, due to this heterogeneity. Synthesis of these results is further limited by omissions of certain themes from some survey studies; for example, very few studies explicitly asked about experiences of harassment and discrimination, which limits our ability to truly understand these rates across studies. Overall, we included many studies with a high risk of bias, which may impact our reported results.

\section{CONCLUSION}

The most consistent barriers experienced by breastfeeding physicians and trainees are lack of adequate space at work and time constraints; these barriers are reported to interfere with duration of breast feeding for women in medicine. Medical leaders should work to address these barriers and future research on this topic should aim to evaluate the impact of interventions.

\section{Twitter Shannon M Ruzycki @ShannonRuzycki}

Contributors AF and AM conceived and designed the study, performed data collection, performed data analysis, and edited the final version of the manuscript. K-TN and MBJ performed data collection, assisted with data analysis, and edited the final version of the manuscript. KL supervised data collection, performed data collection and edited the final version of the manuscript. SMR supervised the study, provided administrative support, contributed to conception and design of the study, performed and supervised data collection, performed data analysis and wrote the first draft of the manuscript.

Funding The authors have not declared a specific grant for this research from any funding agency in the public, commercial or not-for-profit sectors.

Competing interests None declared.

Patient consent for publication Not required.

Provenance and peer review Not commissioned; externally peer reviewed.

Data availability statement Data are available on reasonable request. Data are available from the corresponding authors by reasonable request.

Open access This is an open access article distributed in accordance with the Creative Commons Attribution Non Commercial (CC BY-NC 4.0) license, which permits others to distribute, remix, adapt, build upon this work non-commercially, and license their derivative works on different terms, provided the original work is properly cited, appropriate credit is given, any changes made indicated, and the use is non-commercial. See: http://creativecommons.org/licenses/by-nc/4.0/.

ORCID iD

Shannon M Ruzycki http://orcid.org/0000-0002-8122-2910

\section{REFERENCES}

1 Glauser W. Medicine changing as women make up more of physician workforce. CMAJ 2018;190:E404-5.

2 More Women Than Men Enrolled in U.S. Medical Schools in 2017 [press release]. AAMC: AAMC, 2017.

3 Association CM. Physicians by specialty, sex, and age group. CMA, 2019.

4 Adesoye T, Mangurian C, Choo EK, et al. Perceived discrimination experienced by physician mothers and desired workplace changes: a cross-sectional survey. JAMA Intern Med 2017;177:1033-6.

5 Chatani $Y$, Nomura K, Ishiguro A, et al. Factors associated with attainment of specialty board qualifications and doctor of medical science degrees among Japanese female doctors. Acad Med 2016;91:1173-80.

6 Davids JS, Scully RE, Melnitchouk N. Impact of procedural training on pregnancy outcomes and career satisfaction in female postgraduate medical trainees in the United States. J Am Coll Surg 2017;225:411-8.

7 Gottenborg E, Maw A, Ngov L-K, et al. You can't have it all: the experience of academic hospitalists during pregnancy, parental leave, and return to work. $J$ Hosp Med 2018;13:836-9.

8 Halley MC, Rustagi AS, Torres JS, et al. Physician mothers' experience of workplace discrimination: a qualitative analysis. BMJ 2018;363:k4926.

9 Surawicz CM. Women in leadership: why so few and what to do about it. J Am Coll Radiol 2016;13:1433-7.

10 Sattari M, Levine D, Serwint JR. Physician mothers: an unlikely high risk group-call for action. Breastfeed Med 2010;5:35-9.

11 Juengst SB, Royston A, Huang I, et al. Family leave and returnto-work experiences of physician mothers. JAMA Netw Open 2019;2:e1913054.

12 Pham MT, Rajić A, Greig JD, et al. A scoping review of scoping reviews: advancing the approach and enhancing the consistency. Res Synth Methods 2014;5:371-85. 
13 Peters MDJ, Godfrey C, Mclnerney P, et al. Chapter 11: Scoping reviews. In: Aromataris EMZ, ed. Joanna Briggs institute reviewer's manual. The Joanna Briggs Institute, 2017.

14 Jones LB, Mallin EA. Dr. milk: support program for physician mothers. Breastfeed Med 2013;8:330-2.

15 Group C. Risk of bias instrument for cross-sectional surveys of attitudes and practices: clarity group at McMaster University, 2020. Available: https://www.evidencepartners.com/wp-content/uploads/ 2017/09/Risk-of-Bias-Instrument-for-Cross-Sectional-Surveys-ofAttitudes-and-Practices.pdf

16 Programme CAS. CASP checklist for qualitative studies. Available: https://casp-uk.net/wp-content/uploads/2018/01/CASP-QualitativeChecklist-2018.pdf2018

17 National Heart L, and Blood Institute. Quality assessment tool for before-after (pre-post) studies with no control group us department of health and human services, 2020. Available: https://www.nhlbi. nih.gov/health-topics/study-quality-assessment-tools

18 Orth TA, Drachman D, Habak P. Breastfeeding in obstetrics residency: exploring maternal and colleague resident perspectives. Breastfeed Med 2013;8:394-400.

19 Stack SW, Eurich KE, Kaplan EA, et al. Parenthood during graduate medical education: a scoping review. Acad Med 2019;94:1814-24.

20 Brodribb W, Fallon A, Jackson C, et al. The relationship between personal breastfeeding experience and the breastfeeding attitudes, knowledge, confidence and effectiveness of Australian GP registrars. Matern Child Nutr 2008;4:264-74.

21 Miller NH, Miller DJ, Chism M. Breastfeeding practices among resident physicians. Pediatrics 1996;98:434-7.

22 Stack SW, McKinney CM, Spiekerman C, et al. Childbearing and maternity leave in residency: determinants and well-being outcomes. Postgrad Med J 2018;94:694-9.

23 Holliday EB, Ahmed AA, Jagsi R, et al. Pregnancy and parenthood in radiation oncology, views and experiences survey (proves): results of a blinded prospective trainee parenting and career development assessment. Int J Radiat Oncol Biol Phys 2015;92:516-24.

24 Rangel EL, Lyu $\mathrm{H}$, Haider $\mathrm{AH}$, et al. Factors associated with residency and career Dissatisfaction in childbearing surgical residents. JAMA Surg 2018;153:1004-11.

25 Mwakyanjala EJ, Cowart JB, Hayes SN, et al. Pregnancy and parenting during cardiology fellowship. J Am Heart Assoc 2019;8:e012137.

26 Al-Imari L. Breastfeeding during family medicine residency. Breastfeeding Medicine 2017;12:S6

27 Gupta A, Meriwether K, Hewlett G. Impact of training specialty on breastfeeding among resident physicians: a national survey. Breastfeed Med 2019;14:46-56.

28 Merchant S, Hameed M, Melck A. Pregnancy among residents enrolled in general surgery (PREGS): a survey of residents in a single Canadian training program. Can J Surg 2011;54:375-80.

29 Hutchinson AM, Anderson NS, Gochnour GL, et al. Pregnancy and childbirth during family medicine residency training. Fam Med 2011;43:160-5.

30 Maraolo AE, Ong DSY, Cortez J, et al. Personal life and working conditions of trainees and young specialists in clinical microbiology and infectious diseases in Europe: a questionnaire survey. Eur $\mathrm{J}$ Clin Microbiol Infect Dis 2017;36:1287-95.

31 Sandler BJ, Tackett JJ, Longo WE, et al. Pregnancy and parenthood among surgery residents: results of the first nationwide survey of general surgery residency program directors. J Am Coll Surg 2016;222:1090-6.

32 Ames EG, Burrows HL. Differing experiences with breastfeeding in residency between mothers and Coresidents. Breastfeed Med 2019;14:575-9.

33 Gjerdingen DK, Chaloner KM, Vanderscoff JA. Family practice residents' maternity leave experiences and benefits. Fam Med 1995;27:512-8

34 Merchant SJ, Hameed SM, Melck AL. Pregnancy among residents enrolled in general surgery: a nationwide survey of attitudes and experiences. Am J Surg 2013;206:605-10.

35 Yaman H, Akçam M. Breastfeeding practices of health professionals and care workers in Turkey. Coll Antropol 2004;28:877-84.

36 Farris SR, Vohra R. Breastfeeding patterns in female emergency medicine residents. Acad Emerg Med 2011;18:S193.

37 Landon E, Selk A. Understanding the experiences of obstetrics and gynaecology residents who take parental leave during training in Canada: a needs assessment. J Obstet Gynaecol Can 2018:40:1453-8.

38 Brodribb W, Fallon A, Jackson C, et al. Breastfeeding and Australian GP registrars-their knowledge and attitudes. J Hum Lact 2008;24:422-30.
39 Kacmar JE, Taylor JS, Nothnagle M, et al. Breastfeeding practices of resident physicians in Rhode Island. Med Health $R I$ 2006;89:230-1.

40 Walsh A, Gold M, Jensen P, et al. Motherhood during residency training: challenges and strategies. Can Fam Physician 2005;51:990-1.

41 Anchondo I, Berkeley L, Mulla ZD, et al. Pediatricians', obstetricians', gynecologists', and family medicine physicians experiences with and attitudes about breast-feeding. South Med J 2012:105:243-8.

42 Sattari M, Levine D, Bertram A, et al. Breastfeeding intentions of female physicians. Breastfeed Med 2010;5:297-302.

43 Pearson ACS, Dodd SE, Kraus MB, et al. Pilot survey of female Anesthesiologists' childbearing and parental leave experiences. Anesth Analg 2018.

44 Melnitchouk N, Scully RE, Davids JS. Barriers to breastfeeding for us physicians who are mothers. JAMA Intern Med 2018;178:1130-2.

45 Cantu RM, Gowen MS, Tang X, et al. Barriers to breastfeeding in female physicians. Breastfeed Med 2018;13:341-5.

46 Sattari M, Serwint JR, Shuster JJ, et al. Infant-Feeding intentions and practices of internal medicine physicians. Breastfeed Med 2016;11:173-9.

47 Lerner LB, Baltrushes RJ, Stolzmann KL, et al. Satisfaction of women urologists with maternity leave and childbirth timing. J Urol 2010;183:282-6.

48 Hamilton AR, Tyson MD, Braga JA, et al. Childbearing and pregnancy characteristics of female orthopaedic surgeons. J Bone Joint Surg Am 2012;94:e77

49 Dixit A, Feldman-Winter L, Szucs KA. Parental leave policies and pediatric trainees in the United States. J Hum Lact 2015;31:434-9.

50 Riggins C, Rosenman MB, Szucs KA. Breastfeeding experiences among physicians. Breastfeed Med 2012;7:151-4.

51 Eren T, Kural B, Yetim A, et al. Breastfeeding experiences of female physicians and the impact of the law change on breastfeeding. Turk Pediatri Ars 2018;53:238-44

52 Stack SW, Jagsi R, Biermann JS, et al. Maternity leave in residency: a multicenter study of determinants and wellness outcomes. Acad Med 2019;94:1738-45.

53 Sattari M, Serwint JR, Neal D, et al. Work-place predictors of duration of breastfeeding among female physicians. $J$ Pediatr 2013;163:1612-7.

54 Rangel EL, Smink DS, Castillo-Angeles M, et al. Pregnancy and motherhood during surgical training. JAMA Surg 2018;153:644-52.

55 Arthur CR, Saenz RB, Replogle WH. Personal breast-feeding behaviors of female physicians in Mississippi. South Med J 2003;96:130-5.

56 Sattari M, Levine D, Neal D, et al. Personal breastfeeding behavior of physician mothers is associated with their clinical breastfeeding advocacy. Breastfeed Med 2013;8:31-7.

57 Esan OT, Olajide FO, Olubosede OA, et al. Breastfeeding practices of physician-mothers in Ife and llesa zones, Osun state, Nigeria. Afr J Med Med Sci 2013;42:293-9.

58 Ziai S, Cohen M. Advocacy update: results of CWIM's survey on breastfeeding accommodations in medical residency programs. Canadian Women in Medicine [online], 2020. Available: https:// canadianwim.ca/blogs/news/advocacy-update-results-of-cwim-ssurvey-on-breastfeeding-accommodations-in-medical-residencyprograms [Accessed 25 Feb 2020].

59 Mills G, Dance E, Sabourin J. Experiences of parenting in residency among female residents in Alberta. J Obstet Gynaecol Canada 2019;41:725-6.

60 Sattari M, Levine D, Serwint JR. Physicians' personal breastfeeding experiences: do maternal specialty and study modality make a difference? South Med J 2012;105:675.

61 Sattari M, Rouw E, Mramba L, et al. Breastfeeding and physician mothers-results of an international survey. Breastfeeding Medicine 2017; $12:$ S30

62 Duke PS, Parsons WL, Snow PA, et al. Physicians as mothers: breastfeeding practices of physician-mothers in Newfoundland and Labrador. Can Fam Physician 2007;53:887-91.

63 Sadoh AE, Sadoh WE, Oniyelu P. Breast feeding practice among medical women in Nigeria. Niger Med J 2011;52:7-12.

64 Sattari M. Exclusive breastfeeding among female physicians - A first study. Breastfeeding Medicine 2009;4:245.

65 Sattari M, Levine DM, Neal D, et al. Physician mothers and breastfeeding-do good intentions count? Breastfeeding Medicine 2013;1:S-18.

66 Spatz DL, Kim GS, Froh EB. Outcomes of a hospital-based employee lactation program. Breastfeed Med 2014;9:510-4 
67 Creo AL, Anderson HN, Homme JH. Productive pumping: a pilot study to help postpartum residents increase clinical time. J Grad Med Educ 2018;10:223-5.

68 Porter KK, Stoltzfus MA, Lerie V, et al. A Mother's Room to Support Women in radiology. J Am Coll Radiol 2016;13:1438-9.

69 Robbins JB, Shubeck SP, Kanters AE, et al. Lactation policy and resources for trainees in the Department of radiology. J Am Coll Radiol 2019;16:365-8.

70 Verlander G. Female physicians: balancing career and family. Acad Psychiatry 2004;28:331-6.

71 Finch SJ. Pregnancy during residency: a literature review. Acad Med 2003;78:418-28.

72 Meyers D. Breastfeeding and returning to work in the physician's office. Am Fam Physician 2003;68:2129-33.

73 AAMC News. Wisenberg Brin D. Working Mom, MD: Always on Call [online], 2017. Available: https://www.aamc.org/news-insights/ working-mom-md-always-call [Accessed 25 Feb 2017].

74 MacNamara MMC, Moren K, Taylor LE, et al. State-wide support for physician-mothers who are breastfeeding. Med Health $R$ I 2012;95:9-13.

75 Pesch $\mathrm{MH}$, Tomlinson S, Singer K, et al. Pediatricians advocating breastfeeding: let's start with supporting our fellow pediatricians first. J Pediatr 2019;206:6-7.

76 Grinberg C. Pumped. JAMA 2018;320:977-8.

77 Westrick D. Parenting during residency. Fam Med 2016;48:488.

78 Morris L, Cronk NJ, Washington KT. Response to "parenting during residency". Fam Med 2016;48:488-9.

79 Balk SJ, Yellin TG. Breast-feeding during pediatric residency: is 'breast-fed is best fed' only for others? Pediatrics 1982;70:654.

80 MacDonald KY. Relishing the moment. having a baby in residency. Can Fam Physician 2003;49:1156-7.

81 Chretien KC. Paying at the pump. Ann Intern Med 2008;148:622-3.

82 Lawrence KV. Precious parking lot provisions of care: thoughts from one Mommy, MD. Fam Med 2016;48:814-5.

83 Sarma AA, Nkonde-Price C, Gulati M, et al. Cardiovascular medicine and society: the pregnant cardiologist. J Am Coll Cardiol 2017;69:92-101.

84 Martin CE, Hipp HS, Kottke M, et al. Fertility, pregnancy, and postpartum: a survey of practicing Georgia obstetrician Gynecologists. Matern Child Health J 2019;23:1299-307.

85 Cole S, Arnold M, Sanderson A, et al. Pregnancy during otolaryngology residency: experience and recommendations. Am Surg 2009;75:411-5.
86 Arthur CR, Saenz RB, Replogle WH. The employment-related breastfeeding decisions of physician mothers. J Miss State Med Assoc 2003;44:383-7.

87 Sadoh WE, Sadoh AE. Experiences of HIV positive mothers who chose not to breastfeed their babies in Nigeria. Afr $J$ Reprod Health 2009;13:27-35.

88 Dixit A, Feldman-Winter L, Szucs KA. "Frustrated," "depressed," and "devastated" pediatric trainees: US academic medical centers fail to provide adequate workplace breastfeeding support. $J$ Hum Lact 2015;31:240-8.

89 Al-Imari L, Hum S, Krueger P, et al. Breastfeeding during family medicine residency. Fam Med 2019;51:587-92.

90 The \#MeToo campaign is gaining ground in China. Nature 2018;557:139.

91 Arthur CR, Saenz R, Replogle WH. Breastfeeding education, treatment, and referrals by female physicians. J Hum Lact 2003;19:303-9.

92 Rodriguez Lien E, Shattuck K. Breastfeeding education and support services provided to family medicine and obstetrics-gynecology residents. Breastfeed Med 2017;12:548-53.

93 Sattari MRE, Mramba L, Pina M, et al. Breastfeeding and physician mothers-results of an international survey. Breastfeed Med 2017:12:S30.

94 US Department of Labour. Section 7(r) of the fair labor standards act - break time for nursing mothers provision wage and hour division US department of labour, 2010. Available: https://www.dol. gov/agencies/whd/nursing-mothers/law

95 Pearson ACS, Dodd SE, Kraus MB, et al. Pilot survey of female anesthesiologists' childbearing and parental leave experiences. Anesth Analg 2019;128:e109-12.

96 Commission CHR. Pregnancy \& human rights in the workplace - policy and best practices Canadian human rights commission, 2019. Available: https://www.chrc-ccdp.gc.ca/eng/content/policyand-best-practices-page-2

97 Australian Breastfeeding Association. Breastfeeding \& work: your rights at work, 2017. Available: https://www.breastfeeding.asn.au/ system/files/BFW\%20Fact\%20Sheet\%20-\%20Your\%20rights\% 20at\%20work\%20V1.4\%20052017.pdf

98 Trust NC. Breastfeeding and returning to work, 2019. Available: https://www.nct.org.uk/life-parent/work-and-childcare/returningwork/breastfeeding-and-returning-work

99 Services DoHaH. Breastfeeding report card, 2009.

100 Section on Breastfeeding. Breastfeeding and the use of human milk. Pediatrics 2012;129:e827-41. 